\title{
Pre-Service Teachers' Experiences on the Development of Educational Science Board Games
}

\author{
Wiets Botes ${ }^{1 *}$ \\ 1 Sol Plaatje University, Kimberley, SOUTH AFRICA \\ *Corresponding Author: wiets.botes@spu.ac.za \\ Citation: Botes, W. (2022). Pre-Service Teachers' Experiences on the Development of Educational Science \\ Board Games. European Journal of STEM Education, 7(1), 02. https://doi.org/10.20897/ejsteme/11784
}

Published: February 18, 2022

\begin{abstract}
The expectation is that pre-service teachers that are specializing in the teaching of primary school natural science, ought to make use of teaching approaches that will allow them to engage learners in a joyful yet meaningful science learning experience. One such teaching approach to be considered is regarded as board game-based teaching. This paper investigated how natural science pre-service teachers experienced the development of educational science board games. This study draws on a conceptual understanding of gamebased education, which allows for the integration of topics within board game mechanics, board game aesthetics and board game thinking. This qualitative case study considered a focus-group discussion and photo-voice methodology as data collection techniques to capture the pre-service teachers' experiences on the development of educational science board games. Findings from the study revealed how their engagement in the development of educational science board games had an impact on their personal skill development, their professional teacher development, their development of pedagogical content knowledge, as well as their development of applicable assessment methodology that relates to the teaching of the subject natural science. On the other hand, issues surrounding the learning objectives, the complex design processes, and the lack of relevant materials available to develop the educational science board games were viewed in a less positive light. Findings from the study suggest that science teacher education programmes should be intentional in shaping pre-service teachers' skills to develop educational board games that would complement the quality of their science teaching practice.
\end{abstract}

Keywords: educational science board games, board game-based teaching approach, natural science education, natural science pre-service teachers, natural science pre-service teacher development

\section{INTRODUCTION}

Given the popularity of game playing among individuals young and old, researchers in the field of science education are convinced that the use of educational science board games adds value to a science learning experience (Li and Tsai, 2013; van Roy and Zaman, 2018; Young et al., 2012). Although learners are drawn to games for enjoyment and entertainment, the engaging learning experience of playing an educational board game is a product of the board game approaches that are set out to facilitate positive learning outcomes (Tsai et al., 2019; Yien et al., 2011). Amongst these positive outcomes, is the ability of learners to draw on their intellectual skills such as memorising, comprehending, reasoning and analysing information (Taspinar et al., 2016). Other positive outcomes also include learners being able to communicate information both verbally and non-verbally, using cognitive strategies to engage in problem-solving tasks and activities, employing motor skills to perform tasks and finally expressing attitudes. The learning outcomes identified here are a product of the different types of learning couched 
within a board game-based teaching approach. From the literature, one finds that a board game-based teaching approach promotes active learning, cooperative learning, collaborative learning, learning through problem-solving and learning through role-playing, to name but a few (Gagné, 1985; Sousa and Rocha, 2019).

However, these pedagogical principles solely do not constitute an interesting and attractive educational board game that will necessarily motivate learners to play. Li and Tsai (2013) explain that features such as game rules, game instructions, game design, game interactivity, game feedback and game challenges are key towards eliciting an immersive board game-based learning experience. By drawing on these board game features and pedagogical principles, educators will be in a position to expose learners to a joyful, yet meaningful learning experience. The effectiveness of board game-based learning, specifically in the context of natural science education, has been well documented in recent years (Rowe et al., 2017). A study conducted by Hussein et al. (2019) documented how learners who were exposed to board game-based science learning showed improved cognitive gains in the mastering of topics related to life and living, matters and materials, energy and change and earth and beyond, compared to those learners who received traditional instruction. Work done by Tsai et al. (2019) described how learners' engagement in board game-based learning positively affected their motivation and attitudes to learning topics that relate to the natural science school syllabus.

Given the learning benefits offered by the board game-based teaching approach, some researchers predict that the use of educational science board games is likely to become more mainstream in the coming years, especially in the primary education schooling context (Berland and Lee, 2011). Consequently, the capability of board gamebased teaching raising learners' motivation and interest in learning natural science, has drawn the attention of curriculum planners and developers in the field of initial teacher education (Tsai et al., 2019). For this reason, teacher development programmes are intentional in exposing pre-service teachers in development to the features and pedagogical principles of the board game-based teaching approach (Kaimara et al., 2021). It is against this background, that the School of Education at a selected South African university strives towards creating awareness amongst natural science pre-service teachers in applying features and pedagogical principles of the board gamebased teaching approach in their teaching practicum, as part of their teacher development. In the School of Education, the natural science pre-service teachers are made aware of the educational benefits of game-based learning in their teaching didactic modules. The expectation is that the natural science pre-service teachers be able to design and develop their own educational science board games that are underpinned by the pedagogical principles of board game-based teaching. In doing so, the natural science pre-service teachers are not only required to learn theory and understand why theory is important but also learn to apply theory in their teaching practice, hence the phrase from theory to practice (Epstein, 2019). However, given this task, it will be interesting to unravel how the natural science pre-service teachers experienced the process of developing educational science board games. It is for this reason that this study sought to investigate how the natural science pre-service teachers experienced the development of educational science board games.

Conducting this study is important for several reasons. In the first instance, the study amplifies the pre-service teacher-voice in their quest to develop educational science board games. As teacher educators in a school of education, we also intend to learn from the subjective experiences offered by the pre-service teachers in terms of developing educational science board games. Their rich experiences will come in handy to make us realise how we can better structure our teacher developmental material to cater for a board game-based teaching approach. In addition, their experiences will also come in handy to experiment how the ideals of board game-based education might reflect in other subject specialisations, such as mathematics, technology, and social science education.

\section{RATIONALE FOR THE STUDY}

The School of Education at a selected South African university is intentional in its drive to expose natural science pre-service teachers in development to creative and innovative teaching approaches. One such teaching approach, is referred to as board game-based teaching. In exposing natural science pre-service teachers to the aspects of board game-based teaching, they are made aware of the implications, educational benefits and limitations regarding board game-based education. In addition, the natural science pre-service teachers in School of Education are also tasked to design and develop their own educational science board games. In doing so, the natural science pre-service teachers are required to apply their knowledge and understanding of board game-based education into real-life teaching practice. However, given this task, little to no effort had been made by us as teacher educators in the School of Education to unravel how the natural science pre-service teachers ultimately experienced the process of developing educational science board games. It is with this argument in mind that this paper investigates how the natural science pre-service teachers experienced the development of educational science board games. 


\section{GAME-BASED EDUCATION}

Over the last couple of decades, the use of game-based education has gained momentum as a useful teaching approach (Boghian et al., 2019; Bidarra and Rusman, 2017). Apart from eliciting a joyful learning experience, gamebased education provokes what Greenhalgh et al. (2019) refer to as a "deep and engaging learning experience". The authors explain, that game-based education enables an educator to make use of interactive game-based material in order to stimulate the higher-order thinking of learners (Greenhalgh et al., 2019). Game-based education allows learners to engage in learning activities that require a level of recalling, analysis, application and evaluation of knowledge (Coil et al., 2017).

Some scholars are of the view, that a game-based education allows educators to create educational exercises that are tailored to achieve the requirement of a particular learning outcome (Bidarra and Rusman, 2017). For example, an educator can select a lesson topic and integrate the topic within particular game feature designs such as simulations, role-playing, educational card games and educational board games, to mention a few. Educational board games, in particular, is considered a highly versatile and flexible medium that enables learners to engage in tasks that stimulate learners' cognitive domain (for example, learners' development of knowledge and intellectual skills and abilities), affective domain (for example, learners' shaping of feelings, attitudes, and emotions) and psychomotor domain (for example, learners' physical movement, coordination, and use of motor-skills) (Noda et al., 2019).

Targeting these domains also requires learners to draw on their five senses, which includes learners' ability to see, hear, smell, touch, and move (Chiarello and Castellano, 2017). This echoes the view of Higgins and McFeetors (2019) when they refer to the diverse manner through which learners learn and express themselves in a learning situation. Bidarra and Rusman (2017) add, that the use of educational board games allows educators to formulate lesson goals that are aligned to the instructional objectives of the board game. In following these instructional objectives, learners are motivated to acquire knowledge through engaging in the educational board gameplay. This approach, according to Chiarello and Castellano (2017), serves as a means to initiate learners' creative thought processes.

In addition, it has been suggested that the use of educational board games is key in simplifying learners' understanding of subject-content material (Eriksson et al., 2021). Noda et al. (2019) explain that learners' engagement in educational board games fosters their development of non-cognitive attitudinal skills such as the ability to persevere in a task, be conscientious, and work together as a team by communicating and respecting each other's viewpoints. Another benefit that relates to the learners' engagement in educational board gameplay deals with their development of cognitive skills such as their ability to think, read, learn, remember, reason, and pay attention (Bayeck, 2018). It is for this reason that the use of educational board games is considered valuable in eliciting interactive, cooperative and collaborative learning in the classroom (Higgins and McFeetors, 2019). Boffa et al. (2020) add that learners' engagement in educational board gameplay further results in an element of competitiveness. The latter, in turn, serves to motivate and encourage learners to commit and participate in the educational experience (Hallifax et al., 2019).

Finally, the use of educational board games further allows educators to draw on different types of knowledge. This particular feature creates the possibility for educators to integrate ideas and concepts from other subject disciplines into what Bidarra and Rusman (2017) refer to as a cohesive "world picture". This multi- or transdisciplinary exercise is particularly valuable in making learners aware of the cross-curricular nature of knowledge that informs the school syllabus.

\section{RESEARCH METHODOLOGY}

This study was qualitative in nature and followed a case study research design. The case included that of 7 finalyear natural science pre-service teachers and their experiences regarding the development of educational science board games.

\section{Data Collection and Procedures}

The study made use of two data collection techniques, namely a focus group discussion and photo-voice methodology. Data collection for the study took place over a period of two days within the academic programme of the pre-service teachers. In order to achieve the aim of the study, which was to investigate how natural science pre-service teachers experienced the development of educational board games, a series of research questions were considered. These questions were, as follows:

1. Which skills did the natural science pre-service teachers attain by engaging in the development of educational science board games? 
2. What were the natural science pre-service teachers' most enjoyable experiences in developing educational science board games?

3. What were the natural science pre-service teachers' least enjoyable experiences in developing educational science board games?

The purpose for making use of a focus group discussion was two-fold. In the first instance, the focus group discussion allowed the natural science pre-service teachers to respond to the three research questions of the study. In the second instance, the focus group discussion enabled the natural science pre-service teachers to present their education board games that they have developed to their fellow peers. Characteristic of the focus group discussion, was the free flow of information sharing that commenced through open dialogue and narratives between the researcher and the participants (Gawlik, 2018). In following the focus-group discussion, the pre-service teachers had the freedom to share their subjective views and opinions that relate to the three research questions posed. In following the focus group discussion, my role as researcher was merely to stimulate and facilitate discussions that centred around the three research questions. The verbal responses that derived from the focus group discussion was audio recorded. The audio recording of the focus-group discussion was made secure and password protected. None of the names of the participants where mentioned, instead pseudonyms where used to ensure anonymity in the study. The qualitative data that derive from the focus group discussion was analysed through the use of thematic content analysis whereby the data was verbatim transcribed, thematically coded and categorised as themes.

Apart from the focus group discussion, a photo-voice methodology was also employed as a means to capture rich qualitative data in the form of photographic evidence. Photo-voice methodology is a visual data collection method that allows research participants to make use of photographs to support their individual views and opinions (Wang and Burris, 1997). For this study, the natural science pre-service teachers where encouraged to use photographic evidence of their educational board games that they have developed to support their individualised responses to the three research questions posed. In doing so, a correlation was established between the verbal responses from the focus group discussion and the visual photographic evidence offered by the pre-service teachers. This approach allowed for an in-depth exploration and interpretation of the participants' responses, which promoted the aspect of triangulation in the study.

\section{Trustworthiness in the Study}

Methodological rigor in the study was considered through drawing on measures such as "confirmability", "credibility" and "neutrality" (Creswell and Creswell, 2017). Confirmability, which is the degree to which findings of the study can be confirmed by others, was established through the open-dialogue that surfaced between the researcher and the pre-service teachers during the focus group discussion. The use of photo voice methodology, as another data collection technique, further promoted the confirmability of the data. Credibility and neutrality were confirmed through the researchers' prolonged interactive engagement with the 7 pre-service teachers in the focus group discussion that took place over the course of a day. Also, the findings of the study were also shared with the team of pre-service teachers to ensure that the data were accurately identified, interpreted and described.

\section{Research Setting and Participants}

The research site was situated in a school of education at a selected South African university. The School of Education offers a Bachelor of Education degree with areas of programme specialization in primary and secondary school teaching. From this research site, the population of the study included pre-service teachers who studied for a Bachelor of Education degree. From this population, a purposive sample of 7 final-year pre-service teachers who specialised in the teaching of the subject natural science, opted as participants for the study. All 7 participants identified specialised in primary school teaching.

\section{Positionality of the Researcher}

Positionality "reflects the position that the researcher has chosen to adopt within a given research study" (SavinBaden and Major, 2013:71). Positionality requires the researcher to acknowledge and locate their views, values, and beliefs in relation to the research process (Goacher et al., 2017). Positionality is normally identified by locating the researcher in terms of the subject under investigation, the research participants and the research context.

In this study, I acknowledged my combined roles as researcher and module lecturer of the 7 final year natural science pre-service teachers. Given these combined roles, I was aware of potential power imbalances that might have existed between myself as module lecturer and researcher and my students whom served as the research participants of the study. With this in mind, I was prompted to be cautious of power-dynamics and forms of intimidation that could have existed between myself and the research participants. By no means did my role as module lecturer affect the ethical processes in this study. In addition, my role as module lecturer also did not 
influence the participants to partake in this study since the participants had the right to form part of the study on a voluntary basis.

\section{Ethics}

Permission for this study was granted by the Postgraduate Research Ethics Committee of the University of the Free State (Ethical clearance number-UFS-HSD2018/0073). The natural science pre-service teachers, who from now onwards will be referred to as the research participants of the study, were consulted in advance to give their consent to participate in the study. The participants were assured confidentiality throughout the study and they were also allowed the right to withdraw from the study at any time. A consent form was drawn up and each of the participants signed the consent form. All of the signed consent forms were archived for record purposes.

\section{RESEARCH RESULTS}

The verbal responses from the focus group discussion and the photographic evidence of the educational science board games that the pre-service teachers developed, yielded rich qualitative data. Table 1 provides a synopsis of the main themes with supportive categories that emerged from the data. The table further aligns the themes and corresponding categories with the three research questions of the study. Following this synopsis, an in-depth interpretation and description of the empirical data will be provided.

Table 1. Synopsis of the themes and categories that emerged from the three research questions

\begin{tabular}{|c|c|c|}
\hline Research questions & Themes & Categories \\
\hline \multirow{5}{*}{$\begin{array}{l}\text { 1. Which skills did the natural science } \\
\text { pre-service teachers attain by engaging } \\
\text { in the development of educational } \\
\text { science board games? }\end{array}$} & \multirow{2}{*}{$\begin{array}{l}\text { 1.1. Skills related to individual } \\
\text { development }\end{array}$} & Practices related to creativity \& improvisation \\
\hline & & Practices related to planning \& organisation \\
\hline & \multirow{3}{*}{$\begin{array}{l}\text { 1.2. Skills related to professional teacher } \\
\text { development }\end{array}$} & $\begin{array}{l}\text { Displaying patience \& commitment in designing the } \\
\text { board game }\end{array}$ \\
\hline & & $\begin{array}{l}\text { Selecting appropriate natural science content for the } \\
\text { board game }\end{array}$ \\
\hline & & $\begin{array}{l}\text { Formulating applicable questions to test learners' } \\
\text { understanding of natural science subject content } \\
\text { knowledge }\end{array}$ \\
\hline \multirow{7}{*}{$\begin{array}{l}\text { 2. What were the natural science pre- } \\
\text { service teachers' most enjoyable } \\
\text { experiences in developing educational } \\
\text { science board games? }\end{array}$} & \multirow{2}{*}{ 2.1. Physical design of board game } & Following a hands-on design approach \\
\hline & & Improvisation with recycled goods \\
\hline & \multirow{4}{*}{$\begin{array}{l}\text { 2.2. Pedagogical content knowledge } \\
\text { development }\end{array}$} & Setting instructions \\
\hline & & Structuring questions \\
\hline & & Evaluating learners' practical process skills \\
\hline & & $\begin{array}{l}\text { Establishing an inquiry-based teaching and learning } \\
\text { experience }\end{array}$ \\
\hline & $\begin{array}{l}\text { 2.3. Prototyping the educational science } \\
\text { board game }\end{array}$ & $\begin{array}{l}\text { Testing the functionality of the board game with } \\
\text { peers }\end{array}$ \\
\hline \multirow{2}{*}{$\begin{array}{l}\text { 3. What were the natural science pre- } \\
\text { service teachers' least enjoyable } \\
\text { experience in developing educational } \\
\text { science board games? }\end{array}$} & \multirow{2}{*}{$\begin{array}{l}\text { 3. Issues associated with the design and } \\
\text { implementation of the educational } \\
\text { science board game }\end{array}$} & Unavailability of resources to develop the board game \\
\hline & & $\begin{array}{l}\text { Inability to use the board game in an authentic "real- } \\
\text { life" teaching setting }\end{array}$ \\
\hline
\end{tabular}

\section{Responding to the Research Question 1-Which Skills Did the Natural Science Pre-Service Teachers Attain by Engaging in the Development of Educational Science Board Games?}

The first research question sought to determine "Which skills did the natural science pre-service teachers attain through engaging in the development of educational science board games?" In posing this question to the 7 participants in the focus group discussion, two themes emerged. These themes were identified as "skills related to individual development" and "skills related to professional teacher development". These two themes are briefly described next.

\section{Theme 1.1. Skills related to individual development}

An analysis of the verbal responses of the participants during the focus group discussion revealed that they encountered a level of personal skill development. To be specific, the research participants reported that their involvement in the development of educational science board games enabled them to practice aspects of "creativity" and "improvisation" in terms of the actual design and development of the educational board game. This can be found in the following response: 
A teacher should have various skills in their teaching toolbox, one including being creative. By planning and making the board game I tapped into my creative skill as well as developed my creative skill. I am now aware of much more creative and interesting ways to teach/assess learners' knowledge informally as well as formatively (Participant 3).

Another participant mentioned the following:

I learned the skill of improvising and planning, using what I have to my disposal to create the board game, for example, using old boxes and cheap affordable materials to create the board game. I also developed an artistic skill of creatively using old materials to make the board game (Participant 5).

Both responses by participants 3 and 5 suggest that the task to develop an educational science board game required a level of creativity, improvisation, planning and organization. In support of these verbal responses, photographic evidence of a board game developed by participant 7 resembles the level of creativity, improvisation, planning and organisation that the task required (Figure 1).

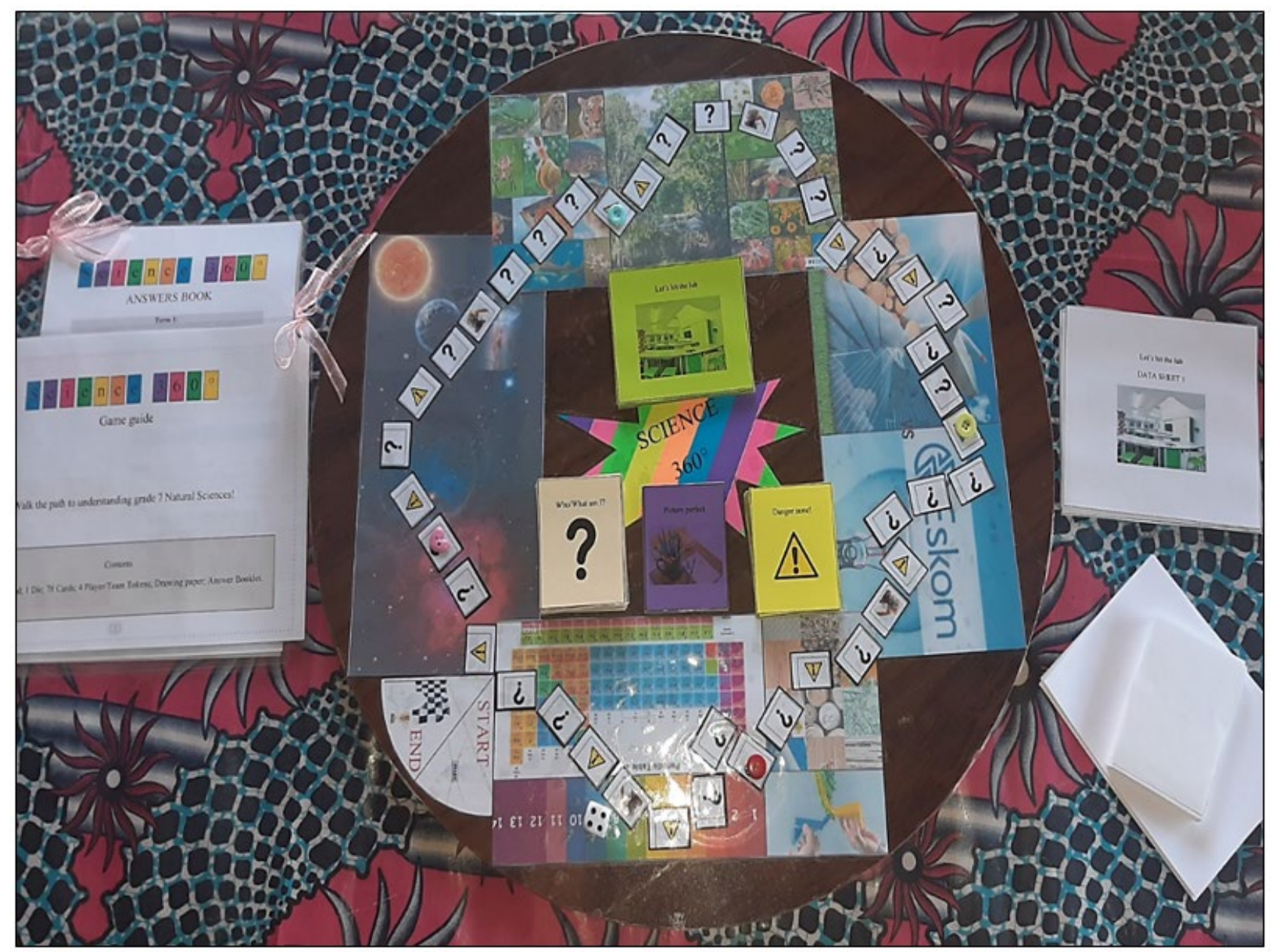

Figure 1. "SCIENCE 360"-A board game developed by research participant 7

In support of the photographic evidence provided by the participant, the description below depicts the level of creativity, planning, improvisation and organisation that were required to design and develop the board game of participant 7. The educational science board game titled "SCIENCE 360" shown here requires learners to compete cooperatively in pairs. The game requires learners to throw a die to determine the number of space/s their team token should move on the board game. Once moved to a certain spot, learners are expected to engage with game cards that contain a variety of questions that tests their knowledge on various natural science topics. To be specific, a closer look at the centre of the board game reveals interesting game cards with catchy labels such as "What am I?", "danger zone!", "picture perfect" and "let's hit the lab". What adds to the creativeness of the game, is that when the game token lands on for instance the question mark icon, then learners are expected to pick up the "what am I?" card. The particular set of cards that form part of the "What am I?" category, requires learners to provide the correct biological term for various biological definitions, thus testing the learners' content knowledge of the subject natural science. Moreover, if the token lands on the "danger zone!" icon, then learners are expected to 
explain certain scientific phenomena in a more descriptive manner, hence allow for the testing of learners' deeper understanding of natural science content knowledge. The opportunity also exists for pairs to land on the "picture perfect" icon. By landing on this icon would require learners to engage in scientific drawings, thus testing the learners' ability to make accurate visual drawings of relevant science topics with complementary labels. Finally, the board game also allows learners to land on the "let's hit the lab" icon. By landing on this icon, learners will be required to draw graphs and tables and interpret scientific data.

\section{Theme 1.2. Skills related to professional teacher development}

The participants' responses to the first research question further suggested that they encountered a level of professional teacher development. In particular, it was reported that their engagement in the task enabled them to display a level of "patience", "commitment" and "dedication" in developing an educational science board game that is "presentable" and would allow learners to "engage in a meaningful learning experience". This can be found in the following two responses.

I had to be very patient in making this game to ensure that everything comes together, and the game looks presentable, from drawing the background to finally pasting the rest of the game (Participant 1).

A similar response was shared by another participant when it was mentioned that:

I had to be very committed in developing the board game. There is a lot of thinking that went into the board game so I had to be dedicated in making the best possible board game that will engage my learners in meaningful learning (Participant 7).

In addition, their responses to the first research question further revealed how their involvement in the development of educational science board games complemented the development of pedagogical content knowledge as a professional teacher skill. Participants 2 and 7 recalled how the task to develop educational science board games challenged them to select topics and formulate questions that are relevant to the subject-syllabus of natural science. This is supported by the following views:

I had to summarise the whole two term's work into 20 short questions and I believe that my summarising skills were developed in the process (Participant 2).

This was similarly the case with participant 7 , when it was mentioned that:

I had to make certain judgements on which type of content I should use that would suit the board game and also make judgements in between the kind of questions to ask from the content. (Participant 7).

To support the verbal responses provided by participants 2 and 7, photographic footage of the educational science board game developed by participant 5 was considered. A closer look at the board game titled "Caught in the web" (see Figure 2 and Figure 3) confirms that the participant selected content topics that related to "plants", "animals" and "insects". These topics inform the natural science syllabus at primary school level. One further finds that participant 5 formulated written questions such as "If a plant did not have a stem, would it be able to grow upright?" and "In which habitat is this specific insect found?"

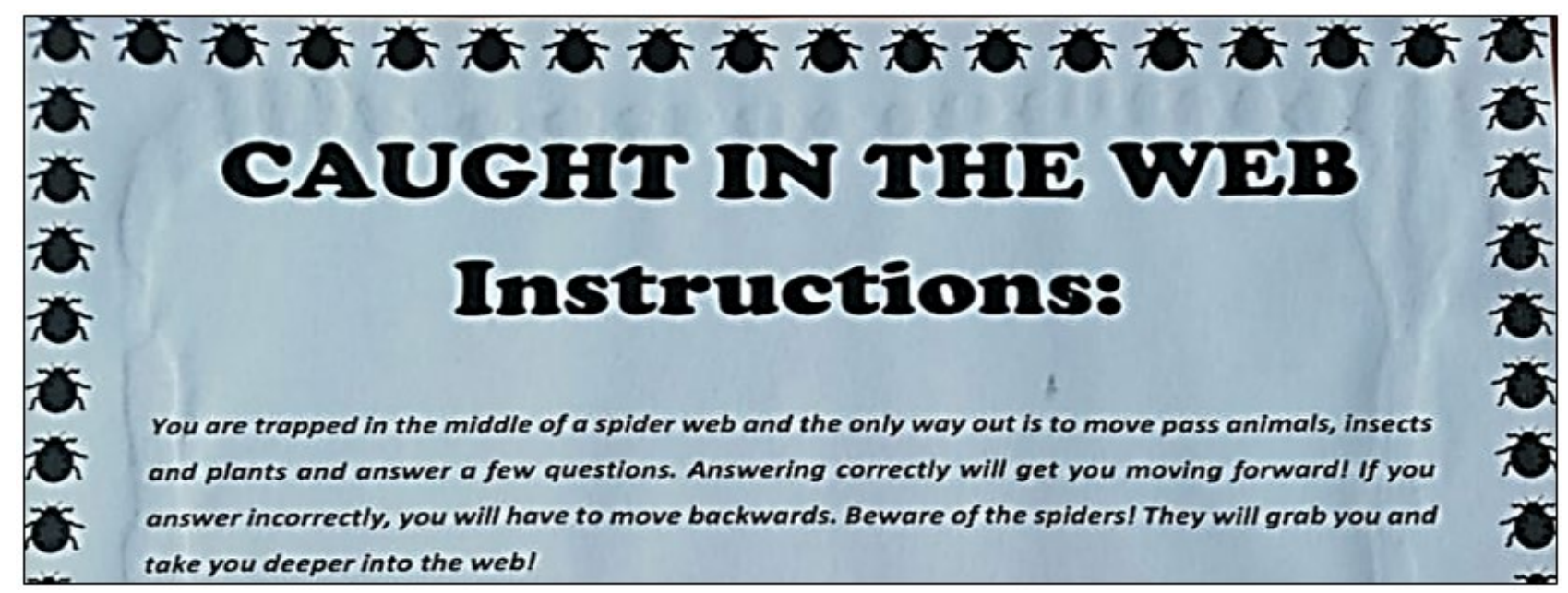

Figure 2. "Caught in the Web" board game instructions 


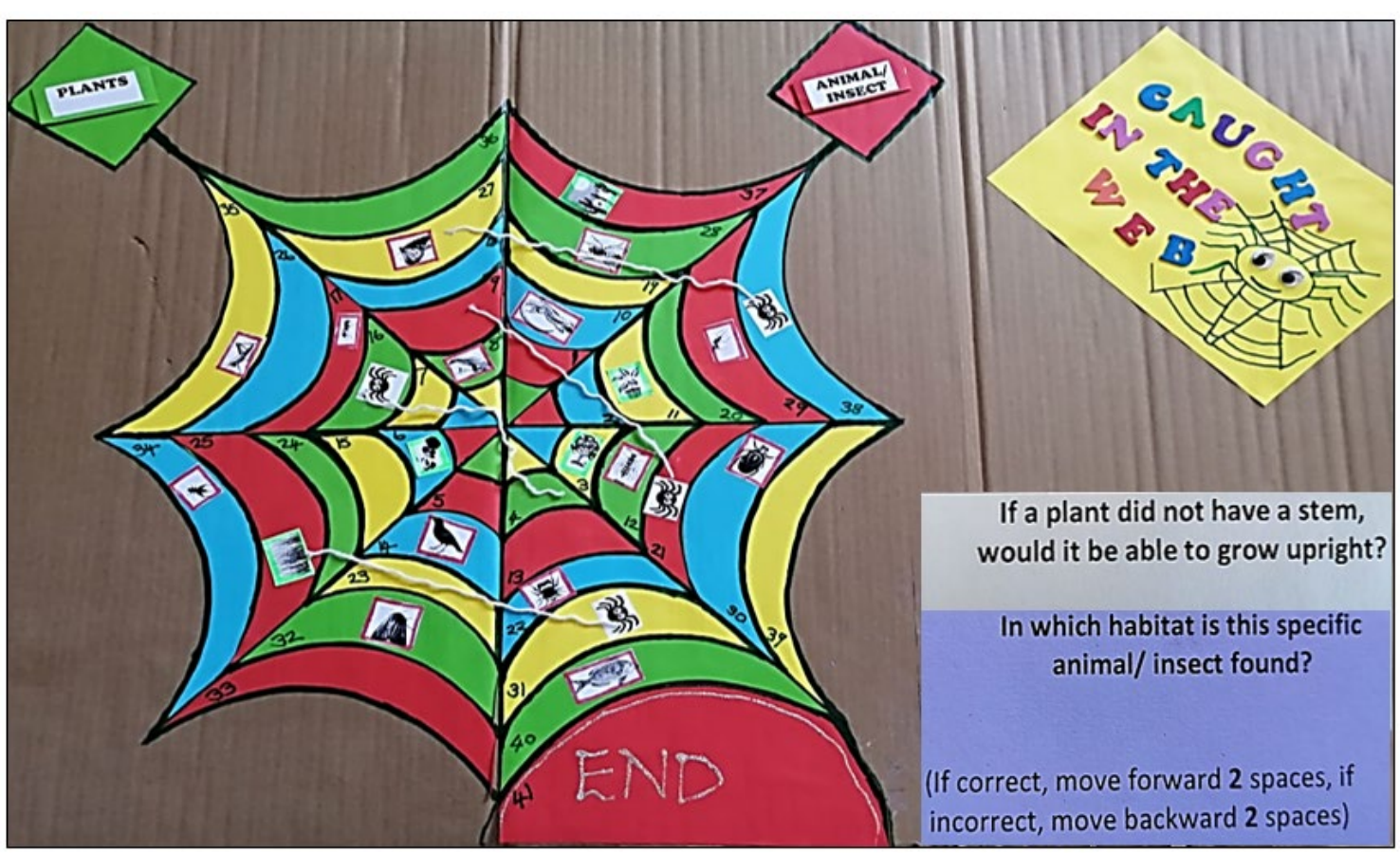

Figure 3. "Caught in the Web" board game

The verbal responses provided by participants 2 and 7, as well as photographic footage provided by participant 5 suggest, that their engagement in the task to develop and educational science board game challenged their ability to select relevant topics and formulate written questions that are associated with the natural science subject syllabus. The latter is considered a key teacher attribute that a natural science educator should possess.

More photographic evidence was provided by participant 3 that demonstrates the participant's ability to formulate different question types such as completion questions (for example, "fill in the missing word that related to the picture"), short response questions (for example, "is the shelter shown in no. 34 a natural or a man-made object?") and explanation questions (for example, "look at the picture and explain what is mean by the word predator") (Figure 4).

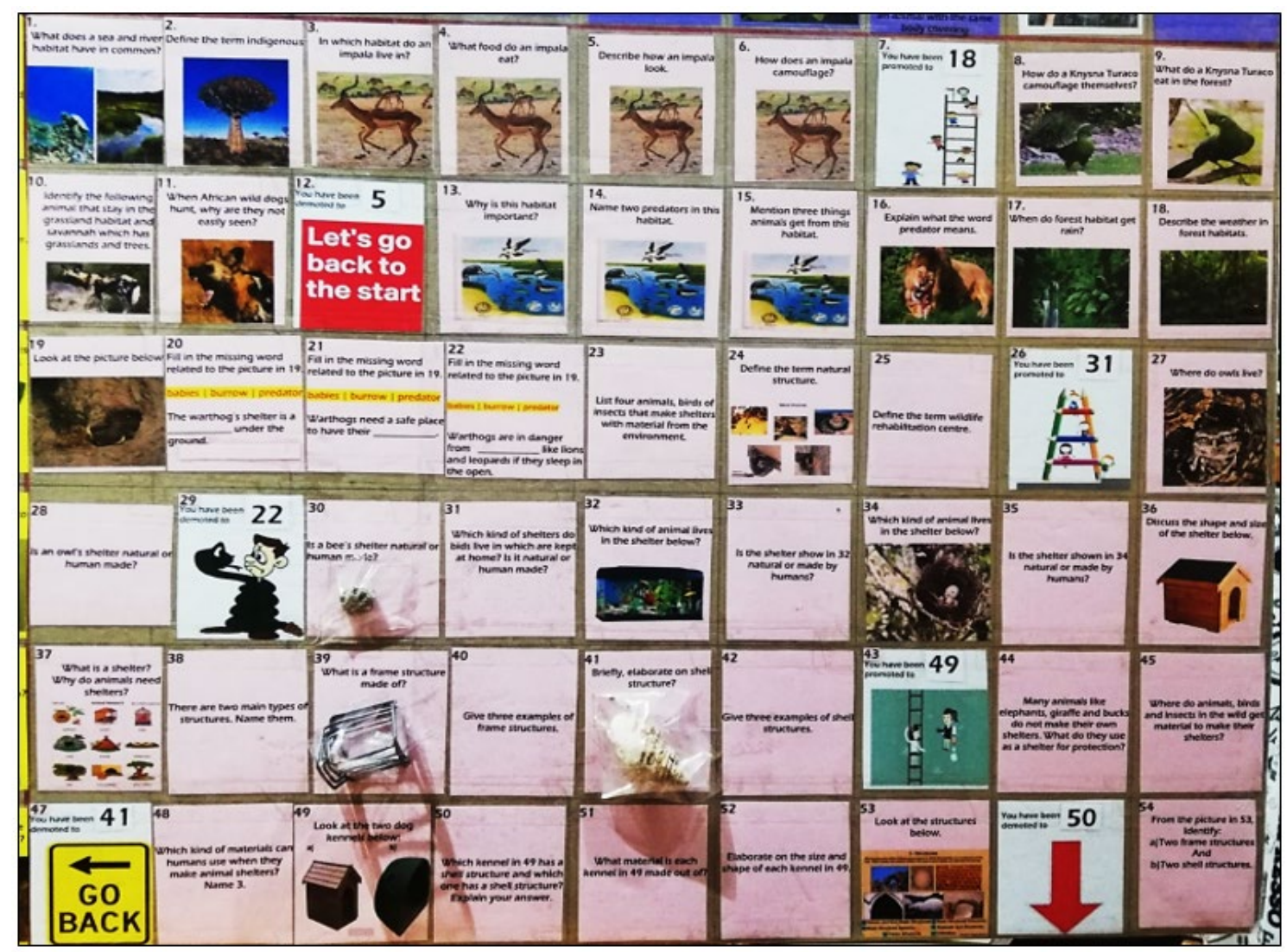

Figure 4. An education science board game inspired by "snakes and ladders" 


\section{Responding to the Research Question 2-What Were the Most Enjoyable Experiences in Developing Educational Science Board Games?}

The purpose of the second research question was to establish the participants' most enjoyable experiences in developing educational science board games. In posing this question to them, four themes emerged from the focus group discussion. Positive experiences, in this regard, were linked to themes that dealt with the "physical design of the science board game", "developing pedagogical content knowledge" and finally "prototyping the science board game with their significant others".

\section{Theme 2.1. Positive experiences related to the physical design of the board game}

The processes involved in the physical design and development of the board games were seen in a positive light, as witnessed in the following response:

The most enjoyable aspect of the game was searching for pictures about the topics and look for interesting/fun facts, learning more about natural sciences and also creating the game, cutting and pasting pictures and designing a game that I would like to play and making the cards (cutting out the cards) (Participant 6).

Participant 5 was also able to share his/her positive experience regarding the physical design of the board game, as witnessed below:

It was also nice being able to use all the papers, magazines and cartons even old plastic milk bottles that I have not gotten rid of so I kind of turned it into something useful (Participant 5).

These two responses depict the level of creativity and improvisation that the participants had to display in their attempt to develop board games from recycled materials. From these responses, the assumption can be made that the participants were challenged to use existing information to create new knowledge, as participant 6 mentioned that he/she had to "search for pictures about topics" while also "looking for interesting fun facts". Apart from the task to use existing knowledge to create new knowledge, the physical "hands-on" design approach of the board game enabled participant 6 to utilise fine motor skills which required her to "cut and paste pictures" while also "cutting out cards for the game". The aspect of improvised thinking also came into play when participant 7 mentioned that he/she was able to make use of "papers, magazines, cartons and old plastic milk bottles" to design the board game.

\section{Theme 2.2. Positive experiences related to the development of pedagogical content knowledge}

Another positive experience that was reported on dealt with the participants' on-going development of pedagogical content knowledge. Participants 1 and 6 mentioned how the project impacted their ability to "create instructions", "develop questions", "evaluate learners' development of science process skills" and "promote the idea of scientific reasoning". Participant 6 had the following to say:

I enjoyed the fact that I could set my own instructions for the questions and design relevant NS questions with answers for the cards. There are easy ones and tricky ones. So my board game will test learners' different intelligences so that no learner is left behind. They will really enjoy it, even the dice is large and spongy, it's an unusual dice and might make learners laugh but it will work well (Participant 6).

In the same vein, participant 1 similarly expressed that:

The most enjoyable aspect is that although it is a board game, the learners will still be engaged in things like hypothesis testing, establishing variables, making calculations and drawing conclusions. So it's basically a mix of fun and scientific reasoning (Participant 1).

Both these responses suggest that the participants had to draw on their pedagogical content knowledge in order to develop the education board game. In the first instance, participant 6 confirmed that the development of the board game allowed her to apply her mind in terms of "structuring relevant instructions on how to play the board game". In addition, participant 6 also had to brainstorm applicable questions to test the learners' content knowledge of the subject natural science. Participant 6 further explained, that some questions of her board game were "easy ones" while other questions "were tricky ones".

This particular response makes it apparent that participant 6 is cognisant of the different levels of questioning as pronounced in Bloom's taxonomy. Participant 1 also made claims about pedagogical content knowledge when she mentioned how she intend to engage learners in scientific reasoning through "hypothesis testing", "clarifying 
variables", "making calculations" and "drawing conclusions". His/her reference to these aspects of scientificreasoning makes one belief that the participant wishes to promote inquiry-based learning amongst the learners.

\section{Theme 2.3. Positive experiences related to the prototyping of the board game}

Another positive experience that was captured dealt the ability of the participants to test the functionality of the board game with their fellow peers and significant others. This was confirmed when participant 3 mentioned that:

Playing a game with my siblings was quite cool. This made me check if the questions asked on the game clear enough for learners to attempt them (Participant 3).

Participant 2 similarly felt that:

This project allowed me to brag a bit with my hard work since I could play the game with my roommate just to check if it works (Participant 2).

Both participants 2 and 3 elaborated on the extent to which they were able to "pilot" the functionality of their educational science board game with their peers and significant others. Surprisingly, the piloting of the board game also had a positive impact on their teacher image. This is supported by the phrases "was quite cool-participant 6" and "I could brag a bit with my hard work-participant 2".

\section{Responding to the Research Question 3-What Were the Least Enjoyable Experiences in Developing Educational Science Board Games?}

In order to portray a comprehensive picture of the participants' experiences further required a reflection on the least enjoyable experiences regarding the board game development process. Their responses to this question pointed to a prominent theme titled "issues associated with the design and testing of the board game".

\section{Theme 3.1. Issues associated with the design and testing of the board game}

Initially, the participants perceived the physical design of their board games from recycled goods in a positive light. However, this was not the case with all of the participants. Some of the participants expressed their frustration with the practical design of the board game due to the unavailability of relevant materials, as witnessed in the extract below:

At the start I had nice ideas to develop the game. But I was also caught off-guard by not having all the stuff needed to make the board game as creative as possible (Participant 5).

The response provided by participant 5 suggests that a shortage of materials restricted his/her ability to develop the board game in a creative manner. Apart from the issue associated with the lack of materials to design the board game, another participant vented his/her frustration in not being able to use the board game in an authentic teaching setting, as witnessed below:

I really wanted to test the board game out during my teaching practice. I mean it was such a mammoth task to create the thing, why not test it? (Participant 1).

\section{DISCUSSION OF FINDINGS}

In the context of natural science teacher education, the expectation is that pre-service teachers that are specializing in the teaching of primary school natural science, ought to make use of a teaching approach that will allow them to engage learners in a joyful yet meaningful science learning experience (Bidarra and Rusman, 2017; Hoy, 2018). One such teaching approach to be considered is referred to as board game-based education (van Roy and Zaman, 2018). Board game-based education in the context of natural science education, allows the educator to teach relevant topics associated with the subject syllabus of natural science through engaging learners in interactive learning materials such as educational science board games (Muell et al., 2020; Huizenga et al., 2017).

As a teaching approach, the use of educational science board games is characterised by different forms of learning namely cooperative learning, cooperative learning and problem-based learning (Ladur et al., 2018). In exposing learners to such forms of learning results in what Higgins and McFeetors (2019) recall as higher-order thinking. It is with these learning benefits in mind, that scholars such as Bidarra and Rusman (2017) and Ofosu- 
Ampong (2020) call upon initial teacher education programmes to be intentional in developing primary school preservice teachers' ability to integrate a board game-based teaching approach in their natural science teaching practice.

In the School of Education at a selected South African university, a group of 7 final-year natural science preservice teachers were tasked to design and develop their own educational science board games that were underpinned by the pedagogical principles of board game-based education. Given this task, this study was interested in unravelling how the natural science pre-service teachers experienced the development of the educational science board games. The natural science pre-service teachers' personal reflections touched base on the different types of skills which they have developed, as well as the most enjoyable and least enjoyable experiences of engaging in the development of educational science board games. In the first instance, from the focus group discussion it was revealed how their engagement in developing the board games shaped practices that relate to "creativity", "improvisation", "innovation", "planning" and "organization".

Additionally, the participants also reported how their engagement in this project shaped professional teacher qualities such as being able to be "patient" and "committed" towards the design of a board game that is "presentable" and would allow for a "meaningful learning experience". Furthermore, they also reported how they could "select applicable topics" from the natural science school syllabus and "formulate written questions" to test learners' knowledge of natural science while playing the board game. Apart from these responses, three captured photographs (see Figure 1, Figure 2, and Figure 3) provided evidence of the level of skill and creativity that the participants displayed in developing the board games. This approach, aligns well with the expectation that preservice teachers who are specialising in the teaching of natural science should be able to demonstrate the skill to teach the subject in a creative and interesting manner (Huizenga et al., 2017).

Apart from reporting on the skills that they had developed, their reflections also touched base on some of the more enjoyable experiences in developing educational science board games. These positive experiences were linked to themes that dealt with "the physical hands-on design of the board game", their "development of pedagogical content knowledge" and their ability to "prototype the board game" with their peers. In terms of the physical hands-on design of the board game, the research participants expressed how they utilised low-cost and recycled goods to design their board games. This was confirmed by a participant who claimed that "It was nice being able to use all the papers, magazines and cartons even old plastic milk bottles that I have not gotten rid of and turn it into something useful-participant 5 ".

Another positive experience that derived from the focus group discussion dealt with their development of pedagogical content knowledge. To be specific, the research participants claimed that their engagement with the task to develop educational science board games challenged their ability to "create board game instructions for learners to follow", "formulate questions to evaluate learners' understanding of natural science knowledge within the board game" and "evaluate learners' development of practical process skills". This approach of linking natural science subject knowledge with teaching knowledge, is what Shulman (1987) decades ago referred to as pedagogical content knowledge.

The assumption can thus be made that the research participants were successful in infusing their natural science subject knowledge and pedagogical content knowledge through the medium of an educational board game (Ladur et al., 2018). This approach aligns well with the idea that educational science board games are considered a highly versatile and flexible medium that allows learners to be tested on the cognitive domain (learners' development of knowledge and intellectual skills and abilities), the affective domain (learners' shaping of feelings, attitudes, and emotions) and the psychomotor domain (learners' physical movement, coordination, and use of the motor-skills) (Liu et al., 2020). Using the concept of game-based learning in education. These domains form part of Bloom's taxonomy of instructional objectives (Noda et al., 2019).

\section{CONCLUSIONS AND IMPLICATIONS}

The purpose of the study was to report on the natural science pre-service teachers' experiences on the development of educational science board games. This was done to introduce and familiarise the natural science pre-service teachers to the notion of a board game-based teaching approach. A board game-based teaching approach, in the context of natural science education, allows for the teaching of science topics through the medium of interactive educational board games. The board games that the pre-service teachers developed allowed for the integration of natural science topics within board game mechanics, aesthetics and board game thinking. This approach allows learners to engage in a playful yet meaningful science learning experience. A board game-based teaching approach is in contrast with more conventional teaching approaches such as direct teaching (Majuri et al., 2018; Muell et. al., 2020).

Verbal responses from the focus group discussion and photographic evidence through the use of photo-voice methodology revealed how the pre-service teachers' engagement in the development of educational science board games impacted both their personal and professional skill development. The team of pre-service teachers also 
expressed their positive experiences regarding the physical "hands-on" design of the board game, their development of pedagogical content knowledge and their ability to prototype their products with their peers. However, one could also learn from the pre-service teachers' less favourable experiences which they encountered in this regard. The necessity of materials to build to board game and the testing of the board game in a real-life teaching context are areas that require attention. On the other hand, given these issues raised this project did indeed make the pre-service teachers acknowledge the value of following a board game-based teaching approach teaching approach. Their engagement in this project did indeed spark their pedagogical thought processes in terms of putting the educational science board games into practice (Chiarello and Castellano, 2017).

Going forward, this study holds a series of implications for future research in the field of pre-service teacher development. Given the learning benefits tied to a board game-based teaching approach, future studies could focus on how educational board games could be tailored for other areas of subject specialisations, such as Mathematics, Technology and Social Science education. Future research could also investigate how pre-service teachers implement educational board games within a teaching practicum experience.

\section{REFERENCES}

Bayeck, R. Y. (2018). A review of five African board games: Is there any educational potential? Cambridge Journal of Education, 48(5), 533-552. https:// doi.org/10.1080/0305764X.2017.1371671

Berland, M. and Lee, V. R. (2011). Collaborative strategic board games as a site for distributed computational thinking. International Journal of Game-Based Learning, 1(2), 65-81. https://doi.org/10.4018/ijgbl.2011040105

Bidarra, J. and Rusman, E. (2017). Towards a pedagogical model for science education: Bridging educational contexts through a blended learning approach. Open Learning: The Journal of Open, Distance and E-learning, 32(1), 6-20. https://doi.org/10.1080/02680513.2016.1265442

Boffa, A., McFeetors, J. and Higgins, M. (2020). Are STEM games intended to be educative? Journal of the Canadian Association for Curriculum Studies, 18(1), 117-118. https://doi.org/10.1002/bmb.2006.494034042644

Boghian, I., Cojocariu, V. M., Popescu, C. V. and Mata, L. (2019). Game-based learning. Using board games in adult education. Journal of Educational Sciences \& Psychology, 9(1), 23-37.

Chiarello, F. and Castellano, M. G. (2017). Board games creation as motivating and learning tool for STEM. Educational Research and Development, 2(3), 13-22. https://doi.org/10.1007/978-3-030-29736-7_22

Coil, D. A., Ettinger, C. L. and Eisen, J. A. (2017). Gut check: The evolution of an educational board game. PLoS Biology, 15(4), 5-19. https://doi.org/10.1371/journal.pbio.2001984

Epstein, J. L. (2019). Theory to practice: School and family partnerships lead to school improvement and student success, in C. L. Fagnano and B. Z. Werber (eds), School, family and community interaction (pp. 39-52). New York: Routledge. https://doi.org/10.4324/9780429305375-4

Eriksson, M., Kenward, B., Poom, L. and Stenberg, G. (2021). The behavioural effects of cooperative and competitive board games in pre-schoolers. Scandinavian Journal of Psychology, 2(3), 78-94. https:// doi.org/10.1111/sjop.12708

Gagné, R. M. (1985). Conditions of learning and theory of instruction. New York: Holt, Rinehart and Winston. Available at: https://agris.fao.org/agris-search/search.do?recordID=US201300622339

Gawlik, K. (2018). Focus group interviews, in M. Ciesielska and D. Jemielniak (eds), Qualitative methodologies in organization studies (97-126). New York: Palgrave Macmillan. https:/ / doi.org/10.1007/978-3-319-65442-3_5

Goacher, R. E., Kline, C. M., Targus, A. and Vermette, P. J. (2017). Using a practical instructional development process to show that integrating lab and active learning benefits undergraduate analytical chemistry. Journal of College Science Teaching, 46(3), 65-73. https://doi.org/10.2505/4/jcst17_046_03_65

Greenhalgh, S. P., Koehler, M. J. and Boltz, L. O. (2019). The fun of its parts: Design and player reception of educational board games. Contemporary Issues in Technology and Teacher Education, 19(3), 469-497. Available at: https://www.learntechlib.org/primary/p/184644/

Hallifax, S., Serna, A., Marty, J. C. and Lavoué, E. (2019). Adaptive gamification in education: A literature review of current trends and developments. Journal of Technology Enhanced Learning, 3(12), 34-45. https://doi.org/10.1007/978-3-030-29736-7_22

Higgins, M. and McFeetors, J. (2019). Board games as play-full pedagogical pivots for STEM teaching and learning. Journal of the Canadian Association for Curriculum Studies, 17(1), 90-110.

Hoy, B. (2018). Teaching history with custom-built board games. Simulation \& Gaming, 49(2), 115-133. https://doi.org/10.1177/1046878118763624

Huizenga, J. C., Ten Dam, G. T. M., Voogt, J. M. and Admiraal, W. F. (2017). Teacher perceptions of the value of game-based learning in secondary education. Computers \& Education, 110(3), 105-115. https://doi.org/10.1016/j.compedu.2017.03.008 
Hussein, M. H., Ow, S. H., Cheong, L. S., Thong, M. K. and Ebrahim, N. A. (2019). Effects of digital game-based learning on elementary science learning: A systematic review. IEEE Access, 7(1), 62465-62478. https://doi.org/10.1109/ACCESS.2019.2916324

Kaimara, P., Fokides, E., Oikonomou, A. and Deliyannis, I. (2021). Potential barriers to the implementation of digital game-based learning in the classroom: Pre-service teachers' views. Technology, Knowledge and Learning, 3(1), 1-20. https://doi.org/10.1007/s10758-021-09512-7

Ladur, A. N., van Teijlingen, E. and Hundley, V. (2018). Whose shoes? Can an educational board game engage Ugandan men in pregnancy and childbirth? BMC Pregnancy and Childbirth, 18(1), 1-8. https://doi.org/10.1186/s12884-018-1704-6

Li, M. C. and Tsai, C. C. (2013). Game-based learning in science education: A review of relevant research. Journal of Science Education and Technology, 22(6), 877-898. https://doi.org/10.1007/s10956-013-9436-x

Liu, Z. Y., Shaikh, Z. and Gazizova, F. (2020). Using the concept of game-based learning in education. International Journal of Emerging Technologies in Learning, 15(14), 53-64. https:// doi.org/10.3991/ijet.v15i14.14675

Majuri, J., Koivisto, J., and Hamari, J. (2018). Gamification of education and learning: A review of empirical literature. Journal of Technology Enhanced Learning, 2(4), 123-144. Available at: http://ceur-ws.org/Vol2186/paper2.pdf

Muell, M. R., Guillory, W. X., Kellerman, A., Rubio, A. O., Scott-Elliston, A., Morales, O. and Brown, J. L. (2020). Gaming natural selection: Using board games as simulations to teach evolution. Evolution, 74(3), 681-685. https://doi:10.1111/evo.13924

Noda, S., Shirotsuki, K. and Nakao, M. (2019). The effectiveness of intervention with board games: A systematic review. Biopsychosocial Medicine, 13(1), 1-21. https:// doi.org/10.1186/s13030-019-0164-1

Ofosu-Ampong, K. (2020). The shift to gamification in education: A review on dominant issues. Journal of Educational Technology Systems, 49(1), 113-137. https://doi.org/10.1177/0047239520917629

Rowe, J. P., Lobene, E. V., Mott, B. W. and Lester, J. C. (2017). Play in the museum: Design and development of a game-based learning exhibit for informal science education. International Journal of Gaming and Computer-Mediated Simulations, 9(3), 96-113. https:// doi.org/10.4018/IJGCMS.2017070104

Savin-Baden, M. and Major, C. (2013). Qualitative research: The essential guide to theory and practice. London: Routledge.

Shulman, L. (1987). Knowledge and teaching: Foundations of the new reform. Harvard Educational Review, 57(1), 123. https://doi.org/10.17763/haer.57.1.j463w79r56455411

Sousa, M. J. and Rocha, A. (2019). Leadership styles and skills developed through game-based learning. Journal of Business Research, 94, 360-366. https://doi.org/10.1016/j.jbusres.2018.01.057

Taspinar, B., Schmidt, W. and Schuhbauer, H. (2016). Gamification in education: A board game approach to knowledge acquisition. Procedia Computer Science, 99(3), 101-116. https://doi.org/10.1016/j.procs.2016.09.104

Tsai, J. C., Cheng, P. H., Liu, S. Y. and Chang, C. Y. (2019). Using board games to teach socioscientific issues on biological conservation and economic development in Taiwan. Journal of Baltic Science Education, 18(4), 634-648. https:// doi.org/10.33225/jbse/19.18.634

van Roy, R. and Zaman, B. (2018). Need-supporting gamification in education: An assessment of motivational effects over time. Computers \& Education, 127(3), 283-297. https:// doi.org/10.1016/j.compedu.2018.08.018

Wang, C. and Burris, M. (1997). Photo voice: Concept, methodology and use for participatory needs assessment. Health Education \& Behaviour, 24(3), 369-387. https:// doi.org/10.1177/109019819702400309

Yien, J. M., Hung, C. M., Hwang, G. J. and Lin, Y. C. (2011). A game-based learning approach to improving students' learning achievements in a nutrition course. Turkish Online Journal of Educational Technology, 10(2), 1-10. Available at: https://www.learntechlib.org/p/217589/

Young, M. F., Slota, S., Cutter, A. B., Jalette, G., Mullin, G., Lai, B., Simeoni, Z., Tran, M. and Yukhymenko, M. (2012). Our princess is in another castle: A review of trends in serious gaming for education. Review of Educational Research, 82(1), 61-89. https://doi.org/10.3102/0034654312436980 